ISSN 0258-7122

Bangladesh J. Agril. Res. 34(1) : 1-4, March 2009

\title{
EFFECT OF SOWING DATE ON THE INCIDENCE OF LOOSE SMUT, FLAG SMUT AND SEED GALL OF WHEAT.
}

\author{
RAJENDER SINGH ${ }^{1}$, M.S. BENIWAL ${ }^{2}$, S.S. KARWASRA ${ }^{3}$ \\ AND HAWA SINGH SAHARAN ${ }^{4}$
}

\begin{abstract}
An experiment was conducted to find out the effect of delay sowing on incidence of loose smut (Ustilago tritici), flag smut (Urocystis agropyri) and seed gall (Anguina tritici) of wheat. Varieties WH 896 and Raj 1555 were free from loose smut at all dates of sowing. At normal date of snwing (25 November) disease incidence varied from $28.18 \%$ (HD 2285) to $43.18 \%$ (Sonalika). Due to delay in sowing by 20 days (15 December), the disease incidence was reduced to $21.33-38.18 \%$ and delay by 35 days (30 December) it was reduced to $18.62 \%$ $32.5 \%$ on all susceptible varieties. At all dates of sowing, varieties WH 283, WI-I 291, WH 896 and Raj 1555 were not infected with flag smut. Other varieties were infected with the disease showing 1.3-14.57, 1.11-11.83 and 0.839.14\% incidence at the sowing dates of 25 November (normal), 15 December (delay) and 30 December (delay), respectively. All of the varieties tested in this study were infected with seed gall nematode and disease incidence increased with delay in date of sowing. The ranges of the disease incidence were 8.16$20.14,12.33-28.91$ and $14.16-36.66 \%$ at first, second thd third date of sowing, respectively.
\end{abstract}

Key Words: Loose smut, flag smut, seed gall nematode, wheat, sowing date.

\section{Introduction}

Loose smut (Ustilago tritici), flag smut (Urocystis agropyri) and seed gall, also known as earcockle (Anguina tritici) are common diseases of wheat. In Haryana state of India, the diseases appear simultaneously causing severe yield loss. Flag smut infects plants/tillers showing twisting and bending of the coleoptiles in the seedling stage with formation of bleached spots on the coleoptiles. Same plants produce smutted spikes that emerged later than the healthy ones. Plants may be infected with both smuts. Lower two-thirds of the spikes are filled with black sori or loose smut fungus. The upper portion of the spike is infected with seed galls, which appears as black galls (Bedi et al., 1959; Aujala and Sharma 1977; and Abu-Ghabrieh and Tamini, 1982). In this country, wheat is sown during mid November to late November. The diseases infect wheat with different degrees of incidence. Report on the effect of different sowing dates and wheat varieties on the incidence of the diseases are not available. Considering the above fact, the present study was undertaken to find out the effect of delay sowing on incidence of loose smut, flag smut, and seed gall of wheat under field condition.

\footnotetext{
${ }^{1-4}$ Department of Plant Pathology, CCS Haryana Agricultural University-Hisar, India.
} 


\section{Materials and Method}

The experiment was conducted at the experimental farm of Chaudhary Charan Singh Haryana Agricultural University-Hisar during three consecutive crop seasons of 2003-2004, 2004-2005, and 2005-2006. Twenty-five wheat varieties commonly cultivated in India were selected for the study. The date of sowing was 25 November, 15 December, and 30 December for each crop season. Previous year, all varieties were grown in the experimental field artificially inoculated with spores of loose smut fungus to serve as inoculums for the experiments of next crop season. Seeds harvested from loose smut inoculated field were also inoculated with flag smut teliospores @ 2g/100g. The viability of flag smut teliospore was $78 \%$. The experiment was laid out in a randomized complete block design with three replications. After final land preparation, the experimental field was divided into three plots maintaining $100 \mathrm{~cm}$ plot to plot distance. Each plot was divided into $90 \mathrm{~cm} \times 20 \mathrm{~cm}$ sub-plot. In each sub-plot, six $200 \mathrm{~cm}$ long furrow were made. Furrow to furrow distance was $15 \mathrm{~cm}$. Soil in each furrow was inoculated with 20 seed gall nematodes. Seeds were sown in continuous lines. Each variety was sown in three separate sub-plots under three plots (replications).The procedure of cultural and intercultural operations were the same as recommended for the area. Numbers of infected and healthy plants in all sub-plots were recorded at the age of 60 days and crop maturity. The incidence was expressed in percentage based on total number of plants. If same plants per tiller had symptoms for all diseases, each was counted separately.

\section{Results and Discussion}

Loose smut infected spikes emerged earlier than healthy spikes. Among 25 varieties of wheat, WH 896 and Raj 1555 were not infected with loose smut pathogen at all dates of sowing. On other 23 varieties, at normal date of sowing (25 November), the incidence of loose smut varied from 28.18 to $43.18 \%$. Due to delay in sowing by 20 days (15 December), the disease incidence was reduced to $21.33-38.18 \%$ and delay by 35 days (30 December), it was reduced to $18.62 \%$ to $32.5 \%$. The results indicated that deLay in sowing may reduce incidence of the disease even on susceptible varieties of wheat (Table 1).

Flag smut symptoms appeared first 45 days after sowing and were followed by earcockle and loose smut symptoms. Irrespective of sowing dates, varieties WH 283, WH 291, WH 896, and Raj 1555 were free from flag smut symptoms. Other varieties were infected with this disease. The degree of incidence of disease decreased gradually with delay in sowing. The ranges of incidence were $1.33-14.57,11-11.83$, and $0.83-9.14 \%$ incidence at the sowing dates of 25 November (normal), 15 December (delay), and 30 December (delay), respectively. (Table 1 ). 
All wheat varieties used in the experiment were infected with seed gall nematode. The incidence of the disease increased with delay date of sowing. The range of seed gall nematode incidence was $8.16-20.14 \%$ at the first sowing date (normal), $12.33-28.91 \%$ at the second sowing date and $14.16-36.66 \%$ at the third sowing date (Table 1 ).

Table 1. Effect of sowing date on incidence of loose smut, flag smut, and seed gall diseases on 25 wheat varieties.

\begin{tabular}{|c|c|c|c|c|c|c|c|c|c|}
\hline \multicolumn{10}{|c|}{ Disease incidence (\%) sowing at } \\
\hline \multirow[t]{2}{*}{ Cultivars } & \multicolumn{3}{|c|}{25 November } & \multicolumn{3}{|c|}{15 December } & \multicolumn{3}{|c|}{30 December } \\
\hline & LS & FS & SG & LS & FS & SG & LS & FS & SG \\
\hline 306 & 9.77 & 10.71 & 18.22 & 37.5 & 11 & $4.7 \mathrm{~T}$ & 28.51 & 5.88 & .57 \\
\hline 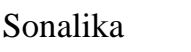 & 18 & 1.33 & & & & & & 0.83 & \\
\hline & 4 & 12 & & 22 & & & 33 & 5 & .83 \\
\hline 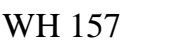 & 9 & 10.83 & & 30.96 & & & 26.66 & 7.83 & .33 \\
\hline & & & & & & & 22 & 00 & 33 \\
\hline $\mathrm{H}$ & 4 & 0.0 & & 2 & $0 .($ & & 27:66 & 0.00 & 4.93 \\
\hline & & 11 & & & & & & & \\
\hline NH5 & 91 & 10.00 & 16. & & 8.1 & 20 & 26.57 & 7.14 & 26.55 \\
\hline & & 12.50 & & & 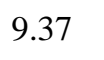 & & 16 & 91 & .33 \\
\hline NH & 0 & 0.00 & 8.1 & 0.0 & 0 & 12.33 & 0.00 & 0.00 & 14.16 \\
\hline onak & .00 & 10.24 & & 26.66 & 3 & & 23.33 & 6.6 & 5.33 \\
\hline HD2 & 54 & 11.14 & 17. & 27.33 & 9.8 & & 24.57 & 6.81 & 26.44 \\
\hline D2 & .18 & 14.57 & 20. & 24 & 11 & 28.91 & 21.77 & 9.1 & 36.66 \\
\hline $\mathrm{D2}$ & 15 & 2.77 & 19 & 27.11 & 1.8 & 22 & 24.37 & 1.17 & 28.57 \\
\hline D2 & 44 & 10.96 & 18. & 28.14 & 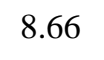 & 21.93 & 25.71 & 7.66 & 27.63 \\
\hline PBW & 33 & 8.66 & & 25.33 & 6.6 & 18.71 & 20.16 & 4.57 & 24.14 \\
\hline BW & & 14.51 & & 28.83 & 10.14 & 19.96 & 24.71 & 8.73 & 26.71 \\
\hline & & 10.42 & & & 7.81 & & 23.66 & 6.44 & 20.83 \\
\hline PBW & 29.62 & 10.87 & 16. & 21.33 & 8.11 & 20.44 & 18.62 & 6.18 & 25.81 \\
\hline & & 0.00 & & & & & 0.00 & 0.00 & 15.73 \\
\hline Raj 3 & 11 & 12.16 & 15.83 & 24.22 & 10.71 & 18.93 & 20.16 & 8.16 & 24.44 \\
\hline Raj 3765 & 28.57 & 14.28 & 20.11 & 24.77 & 11.53 & 24.39 & 20.71 & 8.14 & 28.77 \\
\hline & & 12.66 & & 25.91 & 9.87 & 23.71 & 21.16 & 7.14 & 27.66 \\
\hline UP2338 & 37.67 & 11.77 & 16.66 & 31.14 & 8.91 & 20.55 & 27.14 & 6.93 & 25.16 \\
\hline UP 2425 & & 12.96 & 14.71 & 26.81 & 9.96 & 18.83 & 22.27 & 7.17 & 23.44 \\
\hline C.D $(0.05$ & 2.89 & 3.42 & 3.86 & 2.11 & 3.98 & 4.12 & 2.87 & 3.34 & 4.42 \\
\hline
\end{tabular}

LS=Loose smut, FS=Flag smut, $\mathrm{SG}=$ Seed gall 
Results of the present study showed that only two varieties WH 896 and Raj 1555 were highly resistant or immune to both loose smut and flag smut diseases. Varieties WH 283 and WH 291 were resistant or immune to flag smut at all dates of sowing. Other varieties were susceptible to the disease. Their incidence increased with delay in sowing. No variety was resistant to seed gall nernatode. Delay in sowing enhances the incidence of seed gall. However, loose smut incidence was predominant over earcockle and flag smut at crop maturity. It was noticed that with delay in sowings, loose smut and flag smut incidence was adversely affected, whereas earcockle incidence was enhanced. A reduction in teliospores germination alongwith falling temperatures in November and December and the presence of the nematode $A$. tritici may get more time for infection due to a prolonged germination time in delayed sowing. Similar observations were made by Beniwal et al. (1992) and Pruthi and Gupta (1986) on single spikes, which confirms the finding of present study. Pruthi and Gupta (1986) reported that the presence of fungus and nematodes has an adverse effect on the number, mortality and development of larvae. In some plants, the same tiller showed symptoms of all three diseases. Hence, it is concluded that delay sowing caused reduction in loose smut and flag smut, but boost up the earcockle/seed gall nematode incidence.

\section{References}

Abu-Ghabrieh,W.1 and S.A.Tamini.1982. Reaction of wheat and triticale cultivars to wheat gall nematode and covered smut in Jordan. Dirasat, University of Jordan, 9: 91-96.

Aujala, S.S.and Y.R. Sharma. 1977. Simultaneous occurrence of Ustilago nuda tritici and Urocystis agropyri. Indian Phytopath. 30:262.

Bedi, K.S, Chohan, J.S and Chahal, D.S. 1959. Simultaneous occurrence of Ustilago tritici (Pers) and A. nguina tritici in a single ear of wheat. Indian Phytopath. 12: 187.

M.S. Beniwal, S.S, Karwasra and R.D. Parashar. 1992. Effect of sowing date on the incidence of flag smut of wheat in Haryana. Crop Res. 5(3):598-600

Pruthi, I.J and D.C. Gupta. 1986. Studies on combined occurrence of Ustilago tritici and Anguina tritici. Haryana Agric Univ. J. Res. XVI 4(3):392-394. 